\title{
Global-local anaesthesia: combining paracervical block with intramyometrial prilocaine in the fundus significantly reduces patients' perception of pain during radio-frequency endometrial ablation (Novasure ${ }^{\circledR}$ ) in an office setting
}

\author{
Henrik Skensved
}

Received: 7 August 2011 /Accepted: 29 August 2011 /Published online: 30 December 2011

(C) Springer-Verlag 2011

\begin{abstract}
The aim of this study was to investigate the effectiveness of combining a paracervical block with an intramyometrial block of the uterine fundus on women's perception of pain during Novasure ${ }^{\circledR}$ radio-frequency impedance-controlled endometrial ablation. The study design was a case-control study. The study was conducted in private practice/office setting. The patients were 83 premenopausal women undergoing endometrial ablation due to heavy menstrual periods. The intervention used was hysteroscopic injection of local anaesthetic into the myometrium of the uterine fundus in addition to a paracervical block. There were no adverse events as a consequence of either the anaesthesia or the ablation procedure. All women were asked $60 \mathrm{~s}$ into the active ablation procedure to estimate their perception of pain on a scale from 0 to 10 . Fifty-seven women (69\%) scored a 0, and 77 (92\%) scored 2 or less. None needed to use recovery room facilities after the procedure, and none made use of the access to performing surgeon the evening and night after the procedure. Combining a traditional paracervical block with a transhysteroscopic injection of local anaesthesia into the subendometrial myometrium of the fundus of the uterus significantly reduces women's perception of pain during radio-frequency impedance-controlled endometrial ablation.
\end{abstract}

Keywords Endometrial · Ablation · Local · Anaesthesia . Paracervical $\cdot$ Fundal $\cdot$ Pain $\cdot$ Ropivacaine

H. Skensved $(\bowtie)$

Frederiksgade $2 \mathrm{~A}$,

3400 Hillerod, Denmark

e-mail: henrik@gynaekologen.dk

\section{Background}

Second-generation endometrial ablation devices such as the Novasure ${ }^{\circledR}$ have been developed to enable clinicians to perform treatments under local anaesthesia in an office setting. However, a review of the literature on office-based Novasure ${ }^{\circledR}$ ablations reveals that an acceptable level of pain during active ablation has been difficult to achieve often necessitating simultaneous administration of general anaesthetics, sedatives or tranquillizers, which, in many hospitals and clinics, make the treatments unsuitable for the office setting for which they were originally intended.

\section{Materials and methods}

Between February 2002 and September 2011, premenopausal women referred from their general practitioner with heavy menstrual bleedings refractory to medical treatment or in whom such medical treatments were contraindicated were offered bipolar radio-frequency impedance-controlled endometrial ablation under local anaesthesia.

Women with large myomas, fibroids protruding into the cavity or a cavity depth exceeding $75 \mathrm{~mm}$, were excluded from the study. Likewise, women with cavity depths of less than $35 \mathrm{~mm}$ and women in whom the distance from a caesarean scar to the fundus was less than $35 \mathrm{~mm}$ were not offered endometrial ablation. Furthermore, women with estimated cavity width of less than $30 \mathrm{~mm}$ were not offered endometrial ablation. Women with type 2 fibromas less than $40 \mathrm{~mm}$ in diameter with only marginal protrusion into the uterine cavity not disfiguring it were considered eligible for ablation. Women with known coagulation defects, inborn or iatrogenic, were not offered ablation under local anaesthesia. 
Only women meeting the criteria of ASA group 1 and 2 were included in the study. To exclude intrauterine pathology and distorted cavities, a vaginoscopic microhysteroscopy was performed on all women at their first visit. A transvaginal ultrasound done immediately after the microhysteroscopy (with fluid still in the cavity) allowed measurement of length of the cervical canal, the cavity depth and an estimation of cavity width. The women were advised against fasting before surgery; on the contrary, they were recommended a light breakfast or lunch before treatment. Pre-emptive pain control consisted of $500 \mathrm{mg}$ of naproxen $2 \mathrm{~h}$ before treatment; in women where NSAIDs were contraindicated, naproxen was replaced by $1 \mathrm{~g}$ of paracetamol.

In accordance with national Danish recommendations, all women received antibiotics as a prophylactic (cefalexin $500 \mathrm{mg}$ twice daily for 5 days) commencing $12 \mathrm{~h}$ prior to surgery. After the woman had been placed in the dorsolithotomy position, a paracervical block (PCB) was established using a pudendal syringe with a 6-mm needle tip; repeated aspiration to avert intravascular injection was performed.

Until August 2008, women were treated under PCB only using alfentanil $0.2-0.4 \mathrm{mg}$ intravenously on demand as rescue anaesthesia (Table 1). From September 2008 to March 2011, the PCB consisted of $10 \mathrm{ml}$ of $0.25 \%$ of ropivacaine $\left(\operatorname{Naropin}^{\circledR}\right)$ at 3, 5, 7 and 9 o'clock, respectively (i.e., a total of $40 \mathrm{ml}$ ). Since March 2011, the concentration of ropivacaine has been reduced to $0.2 \%$ in a similar volume.

In addition, $0.5 \mathrm{ml}$ of mepivacaine chloride was injected in the anterior lip to avoid pain from the later placement of a single-tooth Luer Vulsellum. To allow the paracervical block ample time to become fully effective, no uterine manipulation or instrumentation whatsoever was undertaken for $10 \mathrm{~min}$ after the injection of the last dose of ropivacaine. Subsequently, a hysteroscopy was performed using a $5.5-\mathrm{mm}$ hysteroscope (Olympus Europa GmbH, Hamburg, Germany and Richard Wolf GmbH, Knittlingen, Germany) with a 5-F working channel.

Since September 2008, an additional $4 \mathrm{ml}$ of Citanest ${ }^{\circledR}$ (30 mg prilocaine $/ 0.54 \mu \mathrm{g}$ felypressin per millilitre) was placed in the myometrium of the fundal wall through a 5-F Williams cystoscopic injection needle (Cook Medical Inc., Bloomington, IN, USA) (Fig. 1), under direct vision and after

Table 1 Until August 2008, women were treated under PCB only using alfentanil $0.2-0.4 \mathrm{mg}$ intravenously on demand as rescue anaesthesia

\begin{tabular}{lccc}
\hline & $\begin{array}{l}\text { Ropivacaine } \\
0.5 \%\end{array}$ & $\begin{array}{l}\text { Ropivacaine } \\
0.375 \%\end{array}$ & $\begin{array}{l}\text { Ropivacaine } \\
0.25 \%\end{array}$ \\
\hline Number & 25 & 25 & 27 \\
VAS score $(0-10)$ & $4.1( \pm 1.7)$ & $4.9( \pm 1.7)$ & $4.0( \pm 1.6)$ \\
Rescue anaesthesia $(N)$ & 5 & 6 & 6 \\
\hline
\end{tabular}

aspiration. One millilitre of local anaesthetic was placed medial to each of the tubal ostia; the remaining $2 \mathrm{ml}$ was injected with $1 \mathrm{ml}$ on either side of the midline of the fundus (Figs. 2, 3 and 4).

The 8-mm syringe at the end of the Williams needle was introduced at its full length into the myometrium at which stage aspiration was performed in order to confirm nonperforation. Applying pressure on the piston, the needle was subsequently retracted until there was a "loss of resistance", i.e. a decrease in resistance reflecting a position of the tip of the syringe at the superficial layer of the myometrium adjacent to the musculo-mucosal junction.

Link to video 1: http://www.youtube.com/watch? $\mathrm{v}=\mathrm{I} 6 \mathrm{gx} 4 \mathrm{qAsWA}$

To avoid bleeding from obscuring the hysteroscopic view of the uterine cavity at the time of fundal injections, levonorgestrel-releasing intrauterine devices (LNG-IUDs) that where present were not removed until the fundal block had been established.

Link to video 1: http://www.youtube.com/watch? $\mathrm{v}=$ _I $6 \mathrm{gx} 4 \mathrm{qAsWA}$

Hereafter, the cervical canal was dilated to Hegar number 8 and the Novasure ${ }^{\circledR}$ device placed according to the manufacturer's instructions. All the ablation procedures were performed by one surgeon (H.S.). The women's oxygen saturation, heart rate, and blood pressure were monitored during the whole procedure, beginning as the paracervical block was established.

Sixty seconds into the active ablation, all the women were asked the same standardized question with regard to pain. The question was posed by the nurse assisting the surgeon, and the women scored their perception of pain on a scale from 0 to 10 (visual analogue scale (VAS) score).

After the completion of the ablation procedure, a hysteroscopy was performed in order to determine whether the

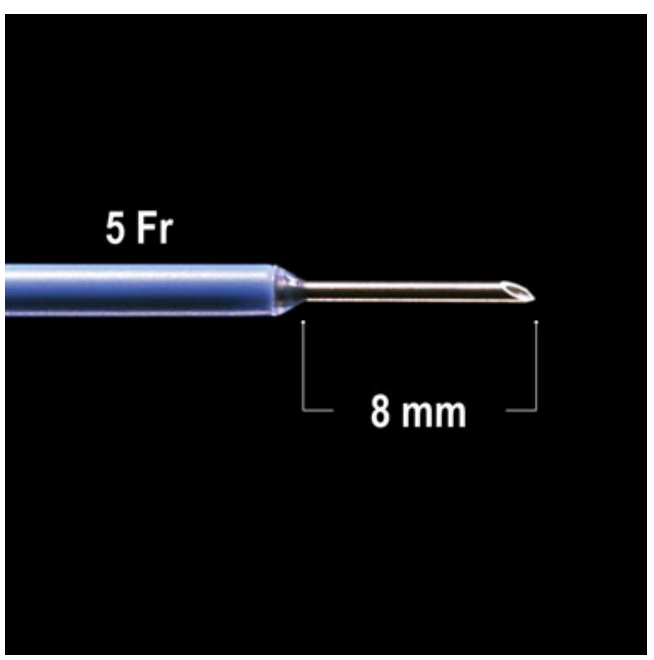

Fig. 1 William cystoscopic injection needle (Cook Medical Inc., Bloomington, IN, USA) 
treatment could be categorized as complete and to exclude any trauma to the uterus. In all cases, the hysteroscopies before and after treatment were digitally recorded.

The women were asked to sit in the clinic's waiting room until they themselves felt fit to leave. The women had access to a stretcher in a separate room if necessary. At departure from the office, the women were encouraged to contact the surgeon on a mobile number on which they could reach him at any time during the first $24 \mathrm{~h}$ after surgery, if so needed. Postoperatively, the women were instructed to take naproxen $250 \mathrm{mg}$ (or $1 \mathrm{~g}$ of paracetamol) 4 and $8 \mathrm{~h}$ after the procedure, respectively. All of the women were contacted by phone the following morning by the same nurse assistant who was present during the ablation procedure. The women included in the study were the first to whom the hysteroscopic fundal block was applied in this clinic.

\section{Findings}

In 99 women, the shape and size of the uterus fulfilled the inclusion criteria. Five women had medical illnesses preventing treatment in an office setting. Two women insisted on a hysterectomy, and nine women did not want treatment under local anaesthesia and thus were referred to a tertiary unit for a transcervical resection of the endometrium under general anaesthesia. Hence, 83 women were included in the study. Twenty-three women (27.7\%) had a retroverted uterus, and 24 women $\left(28.9 \%\right.$ ) had an LNG-IUD (Mirena ${ }^{\circledR}$ ) correctly placed in the uterine cavity at their first visit. All of the ablation procedures were completed with no intra- or postoperative complications. None of the women had any adverse reaction to the paracervical block; ten $(12.0 \%)$ described a slight dizziness or light-headedness after the injection of prilocaine into the fundal myometrium, five of them experienced an additional tingling of the tongue, but in all ten cases, blood pressure, pulse rate and oxygen saturation remained stable and within normal limits. In none of the 83 cases did aspiration after placing the tip of the William needle in the fundal myometrium give suspicion of perforation.

The VAS scores $60 \mathrm{~s}$ into the ablation procedure are presented in Table 2. The average VAS score of 0.6 is significantly lower than the score of 4.0 using a $0.25 \%$ ropivacaine PCB only $(p<0.0001)$. None of the 83 women in the present study asked for alfentanil during the active ablation or immediately after.

None of the 83 women needed to use the surgery's recovery room, and none of the women spent more than $20 \mathrm{~min}$ sitting in the waiting room having tea or coffee after the termination of the Novasure ${ }^{\circledR}$ procedure. During the first evening and night after the procedure, 3 women did not use any pain relief at all, 9 women used paracetamol only, 50 used the $250 \mathrm{mg}$ of naproxen that was prescribed to them prior to surgery, and 21 women used paracetamol and naproxen in combination. None of the women made use of the access to the performing surgeon that was made available to them by mobile phone during the first $24 \mathrm{~h}$ after surgery.

Twenty women returned to work the day after the ablation procedure; the remaining 63 women returned to work 1-3 days after treatment. At 1-month follow-up, none had experienced genital infection. Three of the women (3.6\%) developed haematometra which was easily resolved by dilatation under an intracervical block in the office. All of the 83 women $(100 \%)$ stated that they would recommend the Novasure ${ }^{\circledR}$ procedure as performed above to a friend.

One of the women scoring a 7 had a distorted uterine cavity following resection of the left cornua due to a tubal pregnancy, a (failed) laparoscopic sterilization and a caesarean section including a resection of the remaining right tube. As a consequence, it was very difficult to reach the left corner of the cavity during preablative hysteroscopy, and hence, the block of the left cornua was insufficient.

The other woman with a score of 7 and the woman scoring 5 had completely normal, anteverted uteruses, and there were no problems in placing the intramyometrial injections. They both completed the ablation procedure without needing rescue anaesthesia, and their vital functions did not change during the active ablation.

The additional expense using the cystoscopic needle and $4 \mathrm{ml}$ of Citanest for the fundal block amounted to $€ 33$ for each patient as compared to the cost of the Novasure device of $€ 840$ (Gothia Medical, Bildal, Sweden).

\section{Discussion}

Scientific data on bipolar radio-frequency ablations under local anaesthesia are equivocal. Several trials describing the use of local anaesthesia for Novasure ${ }^{\circledR}$ ablation include use of conscious sedation in addition to the intra- or paracervical block [2-4], making an evaluation of the specific contribution of the local anaesthesia in a single accumulated pain score impossible.

Most studies did not report specific pain scores [2-6], and therefore, the conclusions that Novasure ${ }^{\circledR}$ under local anaesthesia was feasible could not be supported by specific and comparable data. This again makes it difficult to establish whether the protocol reported is broadly and not only locally acceptable to the women and hence the results generalizable to and reproducible in other settings than the one tested.

One study [7] reported an average VAS score of 5.1 (out of 10) which, however, was obtained $4 \mathrm{~h}$ after the ablation procedure was terminated, making an evaluation of the women's perception of pain during the active endometrial destruction process arbitrary. This is also the case with the latest published study, in which the participating women 
were not asked until $30 \mathrm{~min}$ after the end of the procedure when the average VAS score was 4.18 (out of 10) [8]. The latter result is in line with the VAS scores we obtained using a PCB as the sole anaesthetic (Table 1).

Only one study reported VAS scores obtained during the actual ablation procedure [9], and the average VAS score here was $7.7( \pm 2.0)$ (out of 10). This result was achieved despite the use of a deep intracervical block in which the local anaesthetic was placed at the level of the internal os.

The cervix and the lower two thirds of the corpus are innervated from the sacral S1-3 nerves, whereas the upper part of the uterus including the fundus receives its innervation from the thoracic nerves T8-10 [1].

All studies included here [2-4, 6-9] used local anaesthesia injected by the intra- or paracervical route only, thus leaving the nerves from T8-10 in the upper part of the uterus unanaesthetized and hence susceptible to noxious stimuli during the ablation which can explain the high VAS scores in women treated under para- or intracervical block only.

The significance of the separate innervation of the fundus as a key to understanding the insufficient pain relief during intracavitary surgery under PCB is underpinned by results obtained during hysteroscopic sterilization under a paracervical block (which provided effective pain relief for cervical manipulations but did not reduce the pain associated with upper uterine/tubal manipulation when placing the devices) [10] as well as during vacuum aspiration under PCB after incomplete miscarriage [11]. These results are in line with conclusions in the latest Cochrane review on PCB for uterine interventions [12].

Investigators have sought to solve the above dilemma by intrauterine installation of local anaesthetics in the form of liquid, aerosol, or gel, but positive effects of such procedures have not been demonstrated in practice [13]. Thurkow (2005,

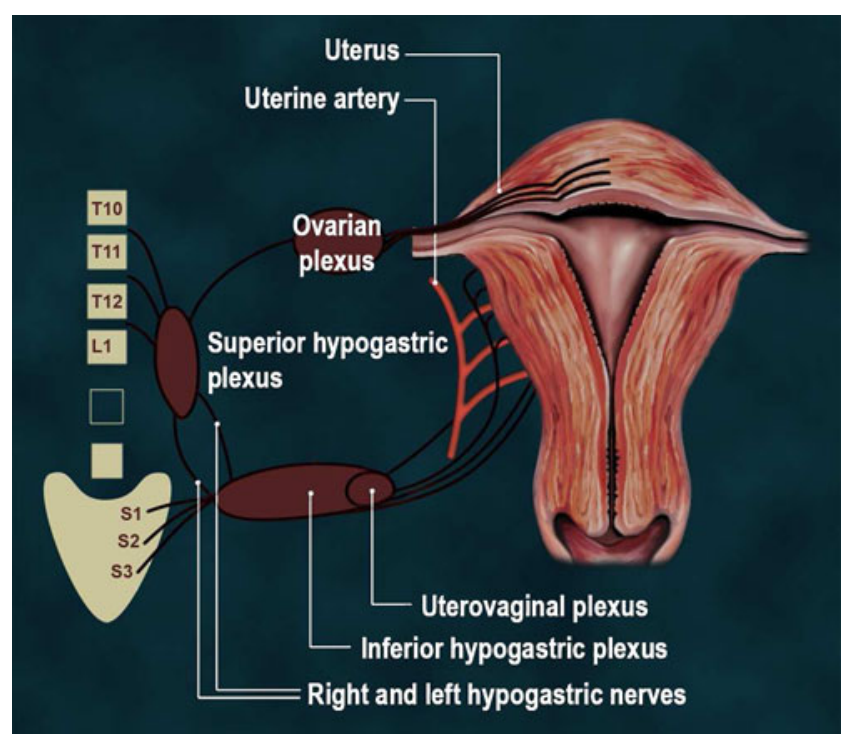

Fig. 2 The innervation of the uterus

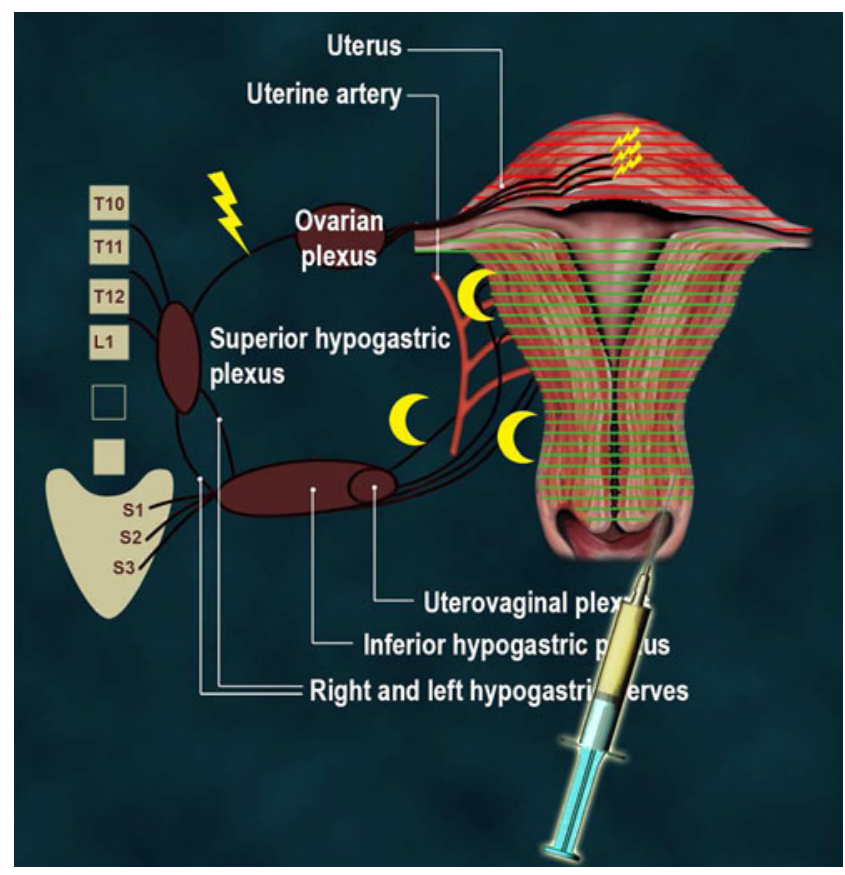

Fig. 3 Anaesthetic coverage of an intra- or paracervical block only

personal communication) speculated that one way of addressing the above problem could be transhysteroscopically injected local anaesthesia in the fundus as a means of blocking the nerves to the upper part of the uterus.

This is the first published study where the paracervical block is combined with a hysteroscopically guided, submucosal, intramyometrially injected local anaesthetic into the upper part of the body of the uterus as the sole anaesthesia for endometrial ablation.

Ropivacaine was selected for the PCB because it is low toxic and long acting covering the first $3-4 \mathrm{~h}$ of the postoperative period when risk of painful uterine cramping

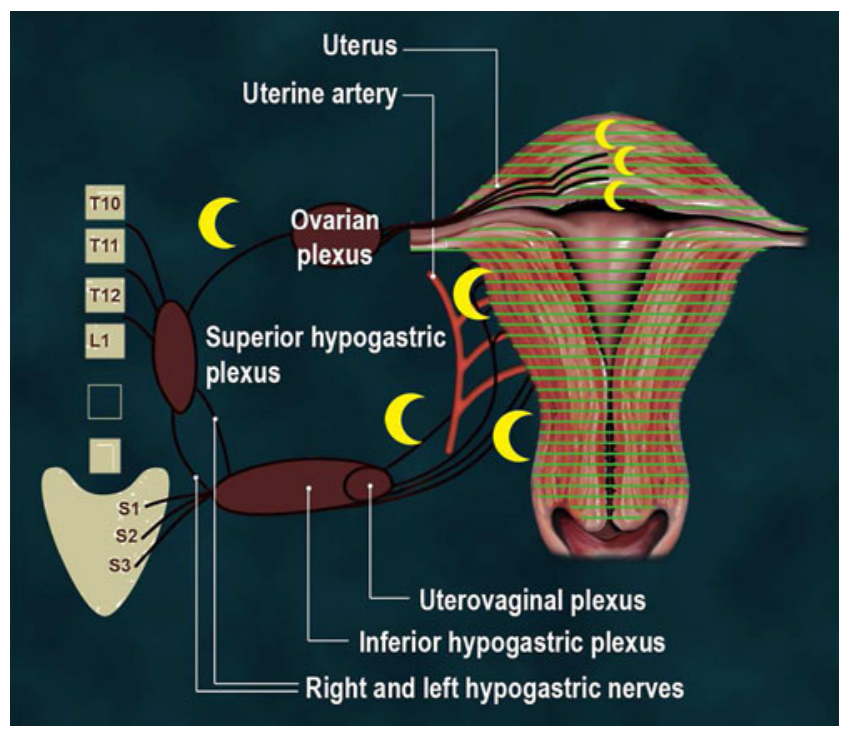

Fig. 4 Anaesthetic coverage of the global-local anaesthesia 
Table 2 VAS score (0-10) $60 \mathrm{~s}$ into active Novasure endometrial ablation

Results from 83 consecutive ablations September 2008 to September 2011

Pain score 0 (zero) 57 (69\%)

Pain score 1 (one) 14 (17\%)

Pain score 2 (two) $5(6 \%)$

Pain score 3 (three) $5(6 \%)$

Pain score 7 (seven) $2(2 \%)$

is at its highest. Ropivacaine at high concentrations produces vasodilation, but a study of infiltration anaesthesia demonstrated that $0.25 \%$ ropivacaine decreases skin blood flow in man [14]. Hence, it is possible that ropivacaine has a similar vasoconstrictive effect on the uterine vessels, but no studies exist to support (or contradict) this. In order to avoid systemic side effects in case of accidental intravasal injection, no epinephrine or any other vasoconstrictor was added to the ropivacaine.

Whereas a high-volume/low-concentration ropivacaine solution was chosen for the PCB, the high-concentration/ low-volume prilocaine solution was chosen for the fundal block in order to minimize the risk of larger subendometrial depots of liquid interfering with the registration of tissue impedance on which the control of the radio-frequency ablation is based.

Maximum dose recommendations concerning local anaesthetics should ideally, as stressed by Scott [15], take into consideration factors such as varying absorption at different injection sites (such as the parametrium) as well as patient characteristics (e.g. age). However, no such ideal recommendations exist.

Compared to the maximum dose of ropivacaine of $300 \mathrm{mg}$ officially recommended in Finland, Japan and the USA and the maximum dose of prilocaine of $400 \mathrm{mg}$ officially recommended in Finland and Sweden [16], the doses of $100 \mathrm{mg}$ of ropivacaine (subsequently $80 \mathrm{mg}$ ) and $135 \mathrm{mg}$ of prilocaine used in the present study are well within the limits of these guidelines.

Breuninger et al. [17] used up to $150 \mathrm{ml}$ of a mixture of $50 \mathrm{ml} 1 \%$ ropivacaine, $50 \mathrm{ml}$ of $2 \%$ prilocaine and $400 \mathrm{ml}$ of Ringer's solution as local anaesthesia in 2,257 patients undergoing minor surgical procedures (excision of dermal tumours and scars as well as transplantations in the head and neck region) without a single major or minor incident involving the local anaesthesia. This result further indicates that the combination of ropivacaine and prilocaine used here is safe.

The results of the present study deviate significantly from the studies on pain during and after bipolar radiofrequency endometrial ablation hitherto published [7-9]. It should be emphasised that this conclusion is based on findings of a non-randomised controlled study and there- fore may not reliably support the effectiveness and use of intramyometrial anaesthesia in the fundus during endometrial ablation.

Aside from the block of the nerves supplying the fundal region of the uterine cavity used only in this study, part of this difference might also be ascribable to the difference in anaesthetic compound used for paracervical and intracervical block in the studies. The popular use of prilocaine might be attributable to its faster onset of action compared to ropivacaine. However, the study by Breuninger et al. [17] demonstrated that a mixture of prilocaine and ropivacaine, albeit decreasing the median duration of action, at the same time increased the speed of onset.

Consequently, future trials should test various mixtures of prilocaine and ropivacaine for the PCB in order to determine the most optimal combination with regard to onset as well as duration of action. Furthermore, tests of different concentrations of prilocaine for the fundal block can establish the most effective volume and concentration of local anaesthetic.

\section{Conclusion}

The results of this study indicate that through a combination of a high-volume/low-concentration paracervical block and a fundal block, the latter placed in the submucosal myometrium during the preoperative hysteroscopy, it is possible to establish a globally active local anaesthesiathe global-local_-which makes procedures such as the Novasure $^{\circledR}$ endometrial ablation safely performable in a low-tech out-of-hospital office setting with very little discomfort to the patient and without need of additional anaesthetics, sedatives and tranquillizing agents, anaesthesiological support or recovery facilities. Obviously, further studies particularly in the form of randomised controlled trials on a larger scale are necessary.

\section{References}

1. Campbell I (2005) Uterine physiology. Anaesth intensive care med 6:76

2. Cooper J, Gimpelson R, Laberge P, Galen D, Garza-Leal JG, Scott J, Leyland N, Martyn P, Liu J (2002) J Am Assoc Gynecol Laparosc 9:418-428

3. Laberge P, Sabbah R, Fortin C, Gallinat A (2003) J Am Assoc Gynecol Laparosc 10:223-232

4. Baskett TF, Clough H, Scott TA (2005) NovaSure bipolar radiofrequency endometrial ablation: report of 200 cases. J Obstet Gynecol Can 27:473-476

5. Bongers MY, Bourdrez P, Mol BWJ, Heintz APM, Brölmann HAM (2004) Randomised controlled trial of bipolar radiofrequency endometrial ablation and baloon endometrial ablation. BJOG 111:1095-1102 
6. Samuel NC, Karragianniadou E, Clark TJ (2009) Outpatient versus day-case endometrial ablation using the Novasure impedance-controlled ablative system. Gynecol Surg 6:3-9

7. Penninx JPM, Mol BW, Bongers MY (2009) Endometrial ablation with paracervical block. J Reprod Med 54:617-620

8. Kalkat RK, Cartmill SV (2011) Novasure endometrial ablation under local anaesthesia in an outpatient setting: an observational study. J Obstet Gynaecol 31:152-155

9. Clark TJ, Samuel N, Malick S, Middleton LJ, Daniels J, Gupta JK (2011) Bipolar radiofrequency compared with thermal baloon endometrial ablation in the office. Obstet Gynecol 1:109-118

10. Chudnoff S, Einstein M, Levie M (2010) Paracervical block efficacy in office hysteroscopic sterilization: a randomized controlled trial. Obstet Gynecol 115:26-34

11. Gomez PI, Gaitán H, Nova C, Paradas A (2004) Paracervical block in incomplete abortion using manual vacuum aspiration: randomized clinical trial. Obstet Gynecol 103:943-951

12. Tangsiriwatthana T, Sangkomkamhang US, Lumbiganon $P$, Laopaiboon M. (2009) Paracervical local anaesthesia for cervical dilatation and uterine intervention. Cochrane Database of Sys- tematic Reviews 2009, Issue 1. Art. No.: CD005056. doi:10.1002/ 14651858.CD005056.pub2

13. Hassan L, Gannon MJ (2005) Anaesthesia and analgesia for ambulatory hysteroscopic surgery. Best Pract Clin Obstet Gynaecol 19:681-691

14. Cederholm I, Evers H, Löfström JB (1991) Effect of intradermal injection of saline or a local anaesthetic agent on skin blood flow - a methodological study in man. Acta Anaesthesiol Scand 35:208-215

15. Scott DB (1989) Maximum recommended doses of local anaesthetic drugs. Br J Anaesth 63:373-374

16. Rosenberg PH, Veering BT, Urmey WF (2004) Maximum recommended doses of local anesthetics: a multifactorial concept. Reg Anesth Pain Med 29:564-575

17. Breuninger H, Schimek F, Heeg P (2000) Subcutaneous infusion anaesthesia with diluted mixtures of prilocain and ropivacain. Langenbeck's Arch Surg 385:284-289

18. Kalkat RK, Cartmill SV (2011) Novasure endometrial ablation under local anaesthesia in an outpatient setting: an observational study. J Obstet Gynaecol 31:152-155 